\title{
The next generation of immunotherapy: keeping lung cancer in check
}

\author{
Ashwin Somasundaram ${ }^{1}$ and Timothy F. Burns ${ }^{1,2^{*}}$
}

\begin{abstract}
Lung cancer is the deadliest malignancy with more cancer deaths per year than the next three cancers combined. Despite remarkable advances in targeted therapy, advanced lung cancer patients have not experienced a significant improvement in mortality. Lung cancer has been shown to be immunogenic and responsive to checkpoint blockade therapy. Checkpoint signals such as CTLA-4 and PD-1/PD-L1 dampen T cell activation and allow tumors to escape the adaptive immune response. Response rates in patients with pretreated, advanced NSCLC were much higher and more durable with PD-1 blockade therapy compared to standard-of-care, cytotoxic chemotherapy. Therefore, PD-1 inhibitors such as nivolumab and pembrolizumab were rapidly approved for both squamous and nonsquamous lung cancer in the pretreated population. The advent of these new therapies have revolutionized the treatment of lung cancer; however, the majority of NSCLC patients still do not respond to PD-1/PD-L1 inhibition leaving an unmet need for a large and growing population.

Immunotherapy combinations with chemotherapy, radiation therapy, or novel immunomodulatory agents are currently being examined with the hope of achieving higher response rates and improving overall survival rate. Chemotherapy and radiation therapy has been theorized to increase the release of tumor antigen leading to increased responses with immunotherapy. However, cytotoxic chemotherapy and radiation therapy may also destroy actively proliferating $T$ cells. The correct combination and order of therapy is under investigation. The majority of patients who do respond to immunotherapy have a durable response attributed to the effect of adaptive immune system's memory. Unfortunately, some patients' tumors do progress afterward and investigation of checkpoint blockade resistance is still nascent.

This review will summarize the latest efficacy and safety data for early and advanced NSCLC in both the treatmentnaive and pretreated settings. The emerging role of immunotherapy for the treatment of small cell lung cancer and malignant mesothelioma will also be discussed.
\end{abstract}

Keywords: Non-small cell lung cancer, Tumor-infiltrating lymphocytes, Regulatory T cells, Programmed death 1 , Programmed death ligand 1, Cytotoxic T-lymphocyte-associated protein 4

\section{Background}

There will be an estimated 224,390 new cases of lung cancer, and an estimated 158,080 lung cancer deaths in 2016. Despite many advances in treatment, the 5-year overall survival for advanced lung cancer is still dismal [1]. Immunotherapy has redefined standard-of-care treatment in the second line, and more recently in the first-line settings, but long-term survival data is still too immature to determine its overall impact in the

\footnotetext{
* Correspondence: burnstf@upmc.edu

${ }^{1}$ University of Pittsburgh Medical Center, Pittsburgh, PA, USA

${ }^{2}$ Division of Hematology-Oncology, Department of Medicine, University of Pittsburgh, Hillman Cancer Center Research Pavilion, 5117 Centre Avenue, Pittsburgh, PA 15213-1863, USA
}

prognosis of lung cancer [2]. For many years, lung cancer had been thought not immunogenic. However, elevated levels of cytotoxic T-lymphocyte-associated protein 4 (CTLA-4), programmed death 1 (PD-1)/programmed death ligand 1 (PD-L1), B7-H3, and B7-H4 on CD8+ tumor-infiltrating lymphocytes (TILs) have been shown in NSCLC [3]. These findings suggest that the immune system plays a much larger role in the control of lung cancer than previously thought.

The adaptive immune system prevents and controls tumor growth in part through $\mathrm{T}$ cell activation. Cancer cells release tumor antigen which is recognized as foreign by antigen presenting cells (APCs) or dendritic cells 
(DCs). Once APCs verify the tumor antigen as foreign via their interaction with $\mathrm{CD} 4+$ and $\mathrm{CD} 8+\mathrm{T}$ cells, the APCs signal for the proliferation of various $\mathrm{T}$ cell subtypes that also recognize the tumor antigen. Many of these lymphocytes become CD8+ cytotoxic T cells that infiltrate the tumor as tumor-infiltrating lymphocytes (TILs), but some become regulatory or suppressor $\mathrm{T}$ cells (Tregs). The normal function of Tregs is to induce several signaling checkpoints that hamper this process of $\mathrm{T}$ cell activation in order to prevent a toxic, autoimmune, positive feedback loop. However, the tumor microenvironment takes advantage of these checkpoint signals in an effort to prevent an anti-tumor $\mathrm{T}$ cell response. Examples of these inhibitory signals that have FDA-approved agents targeting them include the CTLA4 and PD-1/PD-L1 receptors. Antibodies targeting CTLA-4 were initially approved for checkpoint blockade in melanoma but were unfortunately ineffective in NSCLC [4]. Preclinical studies demonstrated that PD-L1 expression correlates with TILs and immunogenicity in NSCLC, which suggested that NSCLC may respond to anti-PD-1/anti-PD-L1 therapy [5]. Furthermore, early safety data studies demonstrated promising efficacy of PD-1 inhibition in NSCLC [6], and antibodies targeting PD-1 have shown remarkable activity in lung cancer as well as melanoma [7] (Fig. 1).

Checkpoint inhibitors, specifically PD-1/PD-L1 inhibition therapy, have been approved in the treatment of certain subgroups of patients with advanced NSCLC. Landmark trials have shown greater overall survival and higher responses to checkpoint inhibition in NSCLC compared to standard-of-care first line and second line chemotherapy along with greater durability of response in a subset of patients. However, still many patients do not respond to these agents. Therefore, new combinations and further evaluation of immunotherapy will be necessary.

\section{Clinical experience with anti-PD-1/anti-PDL-1 agents in lung cancer \\ Pretreated metastatic NSCLC \\ Anti-PD-1 agents}

Early phase studies showed promising safety and response with nivolumab in advanced NSCLC, leading to the development of phase 2/3 studies [8] (Table 1). The phase 3 CheckMate 017 trial compared the anti-PD-1 agent, nivolumab, to docetaxel in patients with advanced pretreated, squamous (SQ) NSCLC, and this study lead to the first FDA approval for immunotherapy in NSCLC. Patients experienced a longer median overall survival (OS) with nivolumab (9.2 months, 95\% CI 7.3-13.3) versus previous standard-of-care chemotherapy: docetaxel (6.0 months, 95\% CI 5.1-7.3) ( $\mathrm{HR}=0.59$, 95\% CI 0.44$0.79, p=0.00025)$. One-year OS was also higher with nivolumab (42\%, 95\% CI 34-50) compared to docetaxel (24\%, 95\% CI 17-31). Median duration of response (DOR) was higher with nivolumab (not reached, 95\% CI 2.9-20.5+) compared to docetaxel (8.4 (1.4+-15.2+)). Median progression-free survival (PFS) was longer with nivolumab (3.5 months, 95\% CI 2.1-4.9) compared to docetaxel (2.8 months, 95\% CI 2.1-3.5) (HR $=0.62,95 \%$ CI $0.47-0.81, p=0.0004)$. This was reflected in a 1 -year

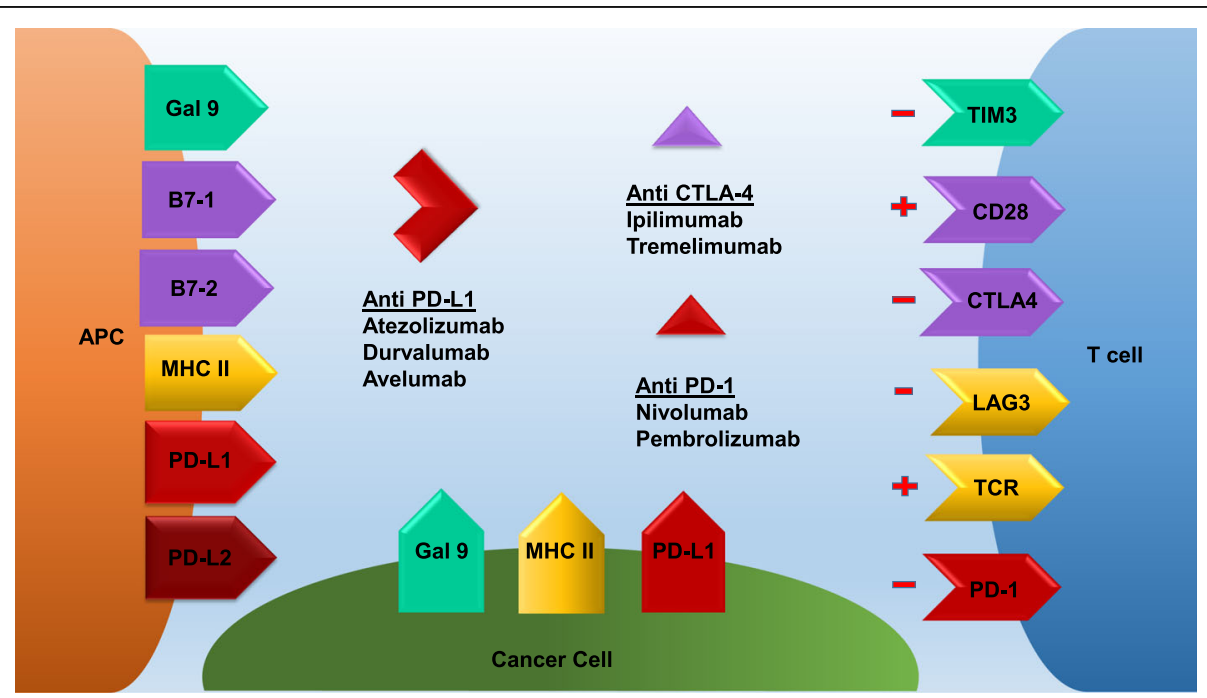

Fig. 1 Multiple receptor-ligand interactions determine T cell response. Binding of the TCR to the APC MHC II receptor presenting antigen leads to antigen specific T cell proliferation and activation. Conversely, LAG-3 binding to the APC MHC can interfere with this process. Furthermore, PD-1 on T cells binding to PD-L1 on APCs, tumor cells, or Tregs can also dampen this response. Nivolumab and pembrolizumab inhibit PD-1, while atezolizumab, durvalumab, and avelumab inhibit PD-L1 leading to T cell activation. B7-1 or B7-2 binding to CD28 also leads to T cell activation. However, if CTLA-4 binds to B7-1 or B7-2 instead, this response is halted. Ipilimumab and tremelimumab inhibit CTLA-4 allowing for T cell activation 
Table 1 Selected completed immunotherapy trials in pretreated, advanced NSCLC

\begin{tabular}{|c|c|c|c|c|c|c|c|c|c|c|}
\hline Trial name & Phase & Histology & Therapy & $\mathrm{mOS}$ & 1-year OS (\%) & DOR & mPFS & 1-year PFS (\%) & mORR (\%) & Ref \\
\hline \multirow[t]{2}{*}{ CheckMate 017} & 3 & SQ & NIVO & 9.2 & 42 & $N R$ & 3.5 & 21 & 20 & [9] \\
\hline & & & DOC & 6 & 24 & 8.4 & 2.8 & 6 & 9 & \\
\hline \multirow[t]{2}{*}{ CheckMate 057} & 3 & NONSQ & NIVO & 12.2 & 50.5 & 17.1 & $N R$ & 18.5 & 19.2 & [10] \\
\hline & & & DOC & 9.4 & 39 & 5.6 & NR & 8.1 & 12.4 & \\
\hline \multirow[t]{3}{*}{ KEYNOTE-010 } & $2 / 3$ & ALL & PEMBRO 2 (PD-L1+) & $9.4(14.9)$ & $N R$ & NR & 3.9 & NR & NR & [12] \\
\hline & & & PEMBRO 10 (PD-L1+) & $10.8(17.3)$ & NR & $N R$ & 4 & NR & NR & \\
\hline & & & DOC & $8.6(8.2)$ & $N R$ & $N R$ & 4 & $N R$ & NR & \\
\hline \multirow[t]{2}{*}{ POPLAR } & 2 & $\mathrm{ALL}$ & ATEZO & 12.6 & NR & NR & 4.2 & NR & 17 & [13] \\
\hline & & & DOC & 9.7 & NR & NR & NR & $N R$ & NR & \\
\hline \multirow[t]{2}{*}{ OAK } & 3 & $\mathrm{ALL}$ & ATEZO & 13.8 & 55 & 16.3 & 2.8 & $N R$ & 14 & [15] \\
\hline & & & DOC & 9.6 & 41 & 6.2 & 4.0 & NR & 13 & \\
\hline KEYNOTE-021 & $1 / 2$ & ALL & PEMBRO + IPI & 17 & $N R$ & 14 & 6 & NR & 24 & [17] \\
\hline
\end{tabular}

PFS that was higher with nivolumab $(21 \%, 95 \%$ CI 1428) compared to docetaxel $(6 \%, 95 \%$ CI 3-12). Finally, median overall response rate (ORR) was higher with nivolumab compared to docetaxel (20 versus 9\%, $p=$ 0.0083). Interestingly, although PD-L1 positivity was not a requirement, patients with $\mathrm{PD}-\mathrm{L} 1+$ tumors showed improved efficacy with nivolumab. However, patients with PD-L1 negative squamous tumors still benefit more from nivolumab compared to docetaxel. Grade 3-4 treatment-related adverse events (TrAEs) occurred in $7 \%$ of patients with nivolumab and $55 \%$ of patients treated with docetaxel along with three docetaxel-related deaths [9].

The phase 3 CheckMate 057 trial examined nivolumab to docetaxel in patients with advanced pretreated, nonsquamous (NONSQ) NSCLC. Median OS was again longer with nivolumab (12.2 months, 95\% CI 9.7-15.0) compared to docetaxel (9.4 months, 95\% CI 8.0-10.7) (HR $=0.73 ; 95 \%$ CI, 0.59-0.89; $p=0.00155)$. One-year OS was higher with nivolumab $(50.5 \%$, 95\% CI $44.6-$ 56.1) compared to docetaxel (39.0\%, 95\% CI 33.3-44.6) as well. Median ORR was higher with nivolumab compared to docetaxel (19.2 versus $12.4 \% ; p=0.0235$; $\mathrm{HR}=$ $0.92,95 \%$ CI $0.77-1.11, p=0.393)$. In addition, DOR and 1-year PFS were also improved. Interestingly, PD-L1 negative, nonsquamous NSCLC did not show a significant benefit of immunotherapy over chemotherapy that was seen in the squamous population $(<1 \%$ PD-L1 OS HR is 0.9 [95\% CI $0.66-1.24$ ], $<5 \%$ PD-L1 OS HR is 1.01 [95\% CI $0.76-1.33$ ], and $<10 \%$ PD-L1 OS HR is 1.00 [95\% CI 0.76-1.31]). Grade 3-5 TrAEs occurred in $10.5 \%$ with nivolumab and occurred in $53.7 \%$ with docetaxel (also one docetaxel-related death) [10].

Early phase $1 / 2$ data from KEYNOTE-001 showed promising safety and efficacy with pembrolizumab in PDL1 positive, advanced NSCLC patients. This biomarker- driven study used its own companion diagnostic and led to the development of phase $2 / 3$ studies [11] (Table 1 ). The KEYNOTE-010 trial was a phase $2 / 3$ trial that compared pembrolizumab to docetaxel in pretreated, PD-L1+ $(>1 \%)$ NSCLC patients and lead to the FDA approval of pembrolizumab with a companion PD-L1 diagnostic [12]. Median OS was 10.4 months for pembrolizumab $2 \mathrm{mg} / \mathrm{kg}$ and 12.7 months for pembrolizumab $10 \mathrm{mg} / \mathrm{kg}$ versus 8.5 months with docetaxel. Overall survival with pembrolizumab versus docetaxel favored pembrolizumab $(\mathrm{HR}=$ $0.71,95 \%$ CI $0.58-0.88 ; p=0.0008$ for pembrolizumab $2 \mathrm{mg} / \mathrm{kg}$ and $\mathrm{HR}=0.61,95 \%$ CI $0.49-0.75 ; p<0.0001$ for pembrolizumab $10 \mathrm{mg} / \mathrm{kg}$ ). However, median PFS was largely similar for pembrolizumab $2 \mathrm{mg} / \mathrm{kg}$, pembrolizu$\mathrm{mab} 10 \mathrm{mg} / \mathrm{kg}$, and docetaxel (3.9, 4.0, and 4.0 months, respectively). Patients with tumors expressing at least $50 \%$ PD-L1 expression had significantly longer OS with pembrolizumab $2 \mathrm{mg} / \mathrm{kg}$ versus docetaxel (median 14.9 versus 8.2 months; $\mathrm{HR}=0.54,95 \%$ CI $0.38-0.77 ; p=0.0002)$ and with pembrolizumab $10 \mathrm{mg} / \mathrm{kg}$ versus docetaxel (median 17.3 versus 8.2 months; $\mathrm{HR}=0.50$, 95\% CI $0.36-0.70 ; p<$ 0.0001). PFS was significantly longer in this patient population with pembrolizumab $2 \mathrm{mg} / \mathrm{kg}$ compared to docetaxel (median 5.0 versus 4.1 months; $\mathrm{HR}=0.59,95 \% \mathrm{CI}$ $0.44-0.78 ; p=0.0001$ ) and pembrolizumab $10 \mathrm{mg} / \mathrm{kg}$ compared to docetaxel (median 5.2 versus 4.1 months; $\mathrm{HR}=0.59,95 \% \mathrm{CI} 0.45-0.78 ; p<0.0001)$. These studies suggested that the degree of PD-L1 positivity may correlate with response rate. TrAEs were less common with pembrolizumab $2 \mathrm{mg} / \mathrm{kg}(13 \%)$ and pembrolizumab $10 \mathrm{mg} / \mathrm{kg}$ (16\%) compared to docetaxel (35\%) [12].

\section{Anti-PD-L1 agents}

Atezolizumab is a newer checkpoint inhibitor that targets PD-L1 compared to the PD-1 inhibitors above. It interferes with the interaction between PD-L1 and PD-1 
as well as PD-L1 and B7-1, but does not interfere with the interaction between PD-L2 and PD-1 which may have biologic and therapeutic implications (Fig. 1). The POPLAR trial, a phase 2 study evaluating atezolizumab compared to docetaxel in 277 patients with pretreated, advanced NSCLC, showed a longer median OS with atezolizumab (12.6 months, 95\% CI 9.7-16.4) compared to docetaxel (9.7 months, 95\% CI 8.6-12.0) ( $\mathrm{HR}=0.73$, 95\% CI 0.53-0.99). Increased PD-L1 expression was associated with an increased $\operatorname{mOS}$ (TC3 or IC3: $\mathrm{HR}=0.49$, 95\% CI $0.22-1.07 ; p=0.068$; TC2/3 or $\mathrm{IC} 2 / 3: \mathrm{HR}=0.54$, 95\% CI $0.33-0.89 ; p=0.014 ; \mathrm{TC} 1 / 2 / 3$ or $\mathrm{IC} 1 / 2 / 3$ : $\mathrm{HR}=$ 0.59 , 95\% CI $0.40-0.85 ; p=0.005$. TC0 and IC0: HR = $1.04,95 \%$ CI $0.62-1.75 ; p=0.871)$. Eleven percent of patients was treated with atezolizumab versus $39 \%$ of patients treated with docetaxel grade 3-4 TrAEs, and one patient in the atezolizumab group versus three patients in the docetaxel group died from a TrAE [13]. Overall, atezolizumab had higher OS compared to docetaxel ( $\mathrm{HR}=0.69,95 \%$ CI 0.52-0.92) across all histologies and PD-L1 subgroups in advanced pretreated NSCLC. Interestingly, longer $\mathrm{OS}$ was also seen in $\mathrm{TC} 0 / \mathrm{IC} 0$ or low PD-L1 expression patients in the squamous NSCLC population [14]. These findings were confirmed in the subsequent OAK trial, a phase 3 study evaluating atezolizumab compared to docetaxel in 850 patients with pretreated, advanced NSCLC, which demonstrated a longer median OS with atezolizumab (13.8 months, 95\% CI 11.8-15.7) compared to docetaxel (9.6 months, 95\% CI 8.6-11.2) $(\mathrm{HR}=0.73,95 \%$ CI $0.62-0.87, p=0.0003)$. Patients benefitted regardless of PD-L status and histology. Given these findings, atezolizumab received FDA approval in this setting [15].

\section{Combination therapy}

Anti-PD-1 agents in combination with ipilimumab are currently being examined in several studies. The Lung Master Protocol (Lung-MAP) or SWOG1400 is a phase $2 / 3$ study evaluating the role of targeted therapies in SQ NSCLC. The Cancer Genome Atlas (TCGA) has detected gene mutations that are potentially amenable to targeted therapy in SQ NSCLC. The Lung MAP study contains multiple phase 2 sub-studies which patients are assigned to sub-studies based on the genetic alterations present in their tumors. Mutations are identified with next generation sequencing. This trial also contains a sub-study for patients who do not have a molecular "match" which tests the combination of nivolumab with ipilimumab compared to standard-of-care nivolumab. This study is ongoing but will hopefully identify novel targeted therapeutic strategies for pretreated SQ NSCLC as well as assess the value of the nivolumab and ipilimumab combination [16]. In addition, the KEYNOTE-021 study contains cohorts which evaluate pembrolizumab in combination with ipilimumab in pretreated, advanced NSCLC. Earlier studies suggested that the use of lower doses (pembrolizumab $2 \mathrm{mg} / \mathrm{kg}$ and ipilimumab $1 \mathrm{mg} /$ $\mathrm{kg}$ ) may be efficacious and reduce combination toxicity. Grade 3-5 TrAEs occurred in $24 \%$ of patients and included diarrhea, and one treatment-related death from pancreatitis. Early evaluation revealed an ORR of $24 \%$ and SD rate of $40 \%$. Median DOR was 14 months, median PFS was 6 months, and median OS was 17 months [17] (Table 1).

\section{Treatment-naïve metastatic NSCLC Monotherapy}

CheckMate 012 also evaluated first-line nivolumab monotherapy in advanced NSCLC and demonstrated ORR was $23 \%$, with $67 \%$ of responses being ongoing (5.3 + to $25.8+$ months). Median PFS was 3.6 months, 24week PFS rate was $41 \%$ (95\% CI, 27-54), and median OS was 19.4 months. Twelve-month and 18-month OS rates were $73 \%$ (95\% CI, 59-83) and 57\% (95\% CI, 42-70). Grade 3 to 4 TrAEs occurred in $19 \%$ of patients with rash being the most common $\mathrm{AE}[18,19]$. CheckMate 026 was a phase 3 , randomized, open-label study of nivolumab monotherapy versus investigator's choice chemotherapy in patients with treatment-naïve, advanced, $\geq 5 \%$ PD-L1 NSCLC. Unfortunately, this trial did not meet its primary endpoint of PFS. This may be possibly due to patient selection as a cutoff of $\geq 5 \%$ PD-L1 expression was utilized compared to a $\geq 50 \%$ cutoff which was explored in the positive KEYNOTE-024 trial described below [20].

KEYNOTE-024 was a phase 3, randomized study evaluating pembrolizumab $200 \mathrm{mg}$ every 3 weeks versus platinum-based chemotherapy in treatment-naive, advanced, $\geq 50 \%$ PD-L1+ NSCLC. Patients were stratified to ECOG status, histology, and region of the world, with PFS as a primary endpoint. Secondary endpoints include OS, ORR, and safety. Median PFS was 10.3 months (95\% CI, 6.7 to NR) with pembrolizumab versus 6.0 months (95\% CI, 4.2 to 6.2) with chemotherapy, and HR for disease progression or death was 0.50 (95\% CI, 0.37 to 0.68 ; $p<0.001)$. Six-month OS was $80.2 \%$ with pembrolizumab versus $72.4 \%$ with chemotherapy group, and HR for death was 0.60 (95\% CI, 0.41 to $0.89 ; p=0.005)$. The response rate was $44.8 \%$ with pembrolizumab versus $27.8 \%$ with chemotherapy. The median duration of response was not reached $(1.9+$ to $14.5+$ months $)$ with pembrolizumab versus 6.3 months $(2.1+$ to $12.6+)$ with chemotherapy. Treatment-related adverse events of any grade were $73.4 \%$ with pembrolizumab versus $90.0 \%$ with chemotherapy, and grade $3+$ TrAEs were $26.6 \%$ with pembrolizumab versus $53.3 \%$ with chemotherapy [21]. In contrast to CheckMate 026, KEYNOTE-024 met its primary endpoint and has established a new standard 
of care in the first-line setting for advanced NSCLC with $>50 \%$ PD-L1 expression. This suggests that a PD-L1 expression cutoff of greater than $50 \%$ may be predictive of response in the first-line setting; however, further study is necessary to determine the role of PD-L1 expression for prognostication and prediction in other settings. Additional trials examining anti-PD-L1 agents such as durvalumab are currently ongoing including a completed phase $1 / 2$ trial (See Table 3).

\section{Combination therapy}

Immunotherapy is also undergoing active evaluation in the first-line setting for advanced NSCLC. Several trials have examined these PD-1/PD-L1 inhibitors in combination with chemotherapy or CTLA-4 inhibitors (Tables 2 and 3).

CheckMate 012 was a phase $1 \mathrm{~b}$, multi-cohort study exploring the safety and efficacy of nivolumab monotherapy versus in combination with platinum-based doublet chemotherapy (PT-DC) for treatment-naïve, advanced NSCLC. Nivolumab was evaluated with cisplatin plus gemcitabine for squamous or cisplatin plus pemetrexed for nonsquamous or carboplatin plus paclitaxel for all histologies. ORR was 33\% for nivolumab $10 \mathrm{mg} / \mathrm{kg}$ plus cisplatin-gemcitabine, $47 \%$ for nivolumab $10 \mathrm{mg} / \mathrm{kg}$ plus cisplatin-pemetrexed, $47 \%$ for nivolumab $10 \mathrm{mg} / \mathrm{kg}$ plus carboplatin-paclitaxel, and $43 \%$ for nivolumab $5 \mathrm{mg} / \mathrm{kg}$ plus carboplatin-paclitaxel. In addition, 2-year OS rates were $25,33,27$, and $62 \%$. Forty-five percent of patients experienced grade 3 or 4 TrAEs most significant for pneumonitis $[18,19]$. This small study suggested that the combining chemotherapy with immunotherapy may be feasible and improve response rates.
CheckMate 012 also evaluated nivolumab alone or in combination with ipilimumab in treatment-naïve, advanced NSCLC patients. Ipilimumab was evaluated with an every 6-weeks-cohort and an every 12-weeks-cohort, and patients were evaluated based on the level of PD-L1 expression. ORR, median PFS, and 1-year OS increased with higher PD-L1 expression and increased frequency of ipilimumab in combination with nivolumab. The combination arm also had greater toxicity and more TrAEs [22, 23]. This trial suggested that this combination may have significant activity and is being examined in several additional trials including the LUNG master protocol in the second-line setting.

KEYNOTE-021, a phase 1/2 study, evaluated the safety and efficacy of pembrolizumab in combination with PTDC in treatment-naïve NSCLC patients regardless of tumor histology. Patient subgroups include the addition of bevacizumab or pemetrexed in the nonsquamous population. One treatment-related death with pericardial effusion occurred in the nonsquamous patient subgroup being treated with bevacizumab [17]. Based on early safety data from KEYNOTE-021, a phase 3, randomized, double-blind study named KEYNOTE-189 is currently evaluating the safety and efficacy of PT-DC alone compared to PT-DC in combination with pembrolizumab in treatment-naïve, nonsquamous NSCLC patients (NCT02578680). Patients are stratified according to smoking status, platinum agent, and PD-L1 status. Primary endpoint will be PFS, and secondary endpoints include ORR, DOR, OS, and safety [24].

In addition, several phase 3 trials examining atezolizumab in combination with a variety of platinum doublets with and without bevacizumab are currently ongoing for all treatment-naïve, advanced NSCLC patients, including

Table 2 Selected completed immunotherapy trials in treatment-naïve NSCLC

\begin{tabular}{|c|c|c|c|c|c|c|c|c|c|c|c|}
\hline $\begin{array}{l}\text { Completed trial } \\
\text { name }\end{array}$ & Phase & Histology & Therapy & $\begin{array}{l}\text { mORR } \\
(\%)\end{array}$ & $\begin{array}{l}<1 \% \text { PD-L1 } \\
\text { ORR }\end{array}$ & $\begin{array}{l}>1 \% \text { PD-L1 } \\
\text { ORR }\end{array}$ & $\begin{array}{l}>50 \% \text { PD-L1 } \\
\text { ORR }\end{array}$ & $\begin{array}{l}<1 \% \text { PD-L1 } \\
\text { PFS }\end{array}$ & $\begin{array}{l}>1 \% \text { PD-L1 } \\
\text { PFS }\end{array}$ & $\begin{array}{l}>50 \% \text { PD-L1 } \\
\text { PFS }\end{array}$ & Ref \\
\hline \multirow[t]{3}{*}{$\begin{array}{l}\text { CheckMate } \\
012\end{array}$} & \multirow[t]{3}{*}{1} & \multirow[t]{3}{*}{ ALL } & NIVO3 & 23 & 14 & 28 & 50 & 6.6 & 3.5 & 8.4 & \multirow[t]{4}{*}{$\begin{array}{l}{[18,} \\
19]\end{array}$} \\
\hline & & & $\begin{array}{l}\text { NIVO3+ } \\
\text { IPIQ12W }\end{array}$ & 47 & 30 & 57 & 100 & 4.7 & 8.1 & 13.6 & \\
\hline & & & $\begin{array}{l}\text { NIVO3+ } \\
\text { IPIQ6W }\end{array}$ & 39 & 0 & 57 & 86 & 2.4 & 10.6 & NR & \\
\hline Trial Name & Phase & Histology & Therapy & $\begin{array}{l}\text { PFS } \\
\text { (months) }\end{array}$ & $\begin{array}{l}\text { 6-month } \\
\text { OS (\%) }\end{array}$ & ORR (\%) & DOR & TrAEs (\%) & $\begin{array}{l}3+\text { TrAEs } \\
(\%)\end{array}$ & & \\
\hline \multirow{2}{*}{$\begin{array}{l}\text { KEYNOTE- } \\
024\end{array}$} & \multirow[t]{2}{*}{3} & \multirow{2}{*}{$\begin{array}{l}\geq 50 \% \\
\text { PD-L1 }\end{array}$} & PEMBROQ3W & 10.3 & 80.2 & 44.8 & NR & 73.4 & 26.6 & & \multirow[t]{3}{*}[21]{} \\
\hline & & & PT-DC & 6.0 & 72.4 & 27.8 & 6.3months & 90.0 & 53.3 & & \\
\hline Trial name & Phase & Histology & Therapy & $\begin{array}{l}\text { PFS } \\
\text { (months) }\end{array}$ & OS & ORR & DOR & TrAEs (\%) & $\begin{array}{l}3+\text { TrAEs } \\
(\%)\end{array}$ & & \\
\hline \multirow{2}{*}{$\begin{array}{l}\text { CheckMate } \\
026\end{array}$} & \multirow[t]{2}{*}{3} & \multirow{2}{*}{$\begin{array}{l}\geq 5 \% \\
\text { PD-L1 }\end{array}$} & NIVO3 & 4.2 & pending & pending & pending & 71 & 18 & & \multirow[t]{2}{*}{ [60] } \\
\hline & & & PT-DC & 5.9 & pending & pending & pending & 92 & 51 & & \\
\hline
\end{tabular}


Table 3 Selected ongoing immunotherapy trials in treatment-naïve, advanced or early NSCLC

\begin{tabular}{|c|c|c|c|c|c|c|}
\hline $\begin{array}{l}\text { Ongoing trial } \\
\text { name }\end{array}$ & Phase & Histology & Therapy & Setting & Endpoints (starting with primary) & Ref \\
\hline KEYNOTE-021 & $1 / 2$ & ALL & PEMBRO + PT-DC & $\begin{array}{l}\text { Advanced, treatment-naïve } \\
\text { NSCLC }\end{array}$ & PFS, ORR, OS, DOR, safety & [17] \\
\hline KEYNOTE-189 & 3 & ALL & PT-DC alone versus PT-DC + PEMBRO & $\begin{array}{l}\text { Advanced, treatment-naïve } \\
\text { NSCLC }\end{array}$ & PFS, ORR, OS, DOR, safety & [24] \\
\hline IMPower 130 & 3 & ALL & PT-DC + ATEZO & $\begin{array}{l}\text { Advanced, treatment-naïve } \\
\text { NSCLC }\end{array}$ & PFS, ORR, OS, DOR, safety & [26] \\
\hline IMPower 111 & 3 & SQ & Gemcitabine/PT + ATEZO & $\begin{array}{l}\text { Advanced, treatment-naïve } \\
\text { NSCLC }\end{array}$ & PFS, ORR, OS, DOR, safety & [29] \\
\hline IMPower 110 & 3 & NONSQ & Pemetrexed/PT + ATEZO & $\begin{array}{l}\text { Advanced, treatment-naïve } \\
\text { NSCLC }\end{array}$ & PFS, ORR, OS, DOR, safety & [28] \\
\hline IMPower 131 & 3 & SQ & Abraxane/PT + ATEZO & $\begin{array}{l}\text { Advanced, treatment-naïve } \\
\text { NSCLC }\end{array}$ & PFS, ORR, OS, DOR, safety & [27] \\
\hline IMPower 150 & 3 & NONSQ & PT-DC/ATEZO & $\begin{array}{l}\text { Advanced, treatment-naïve } \\
\text { NSCLC }\end{array}$ & PFS, ORR, OS, DOR, safety & [25] \\
\hline NEPTUNE & 3 & ALL & $\begin{array}{l}\text { PT-DC alone versus durvalumab + } \\
\text { tremelimumab }\end{array}$ & $\begin{array}{l}\text { Advanced, treatment-naïve } \\
\text { NSCLC }\end{array}$ & PFS, ORR, OS, DOR, safety & [30] \\
\hline MYSTIC & 3 & ALL & Durvalumab + tremelimumab & $\begin{array}{l}\text { Advanced, treatment-naïve } \\
\text { NSCLC }\end{array}$ & PFS, ORR, OS, DOR, safety & [31] \\
\hline PEARLS & $\begin{array}{l}1 \mathrm{~b} / 2- \\
3 \mathrm{a}\end{array}$ & ALL & PEMBRO versus placebo & Adjuvant NSCLC & DFS, OS, lung cancer specific survival & [32] \\
\hline SAKK 16/14 & 2 & ALL & Durvalumab & Adjuvant NSCLC & $\begin{array}{l}\text { Event-free survival at } 1 \text { and } 5 \text { years, } \\
\text { OS, ORR, safety }\end{array}$ & [33] \\
\hline NCT02259621 & 2 & ALL & NIVO & Neoadjuvant NSCLC & Safety & [34] \\
\hline Lung-MAP & $2 / 3$ & SQ & $\begin{array}{l}\text { Biomarker-driven combination with } \\
\text { durvalumab, nivolumab, ipilimumab, } \\
\text { and chemotherapy or targeted therapy }\end{array}$ & $\begin{array}{l}\text { Advanced, pretreated SQ } \\
\text { NSCLC }\end{array}$ & PFS, ORR, OS, DOR, safety & [16] \\
\hline
\end{tabular}

squamous NSCLC and nonsquamous NSCLC using PDL1 positivity as a biomarker [25-29].

NEPTUNE is a phase 3 trial that will evaluate the antiPD-L1 agent durvalumab in combination with tremelimumab (CTLA-4 inhibitor) versus standard chemotherapy in treatment-naive, advanced NSCLC patients. Primary endpoint will include OS, and secondary endpoints will include PD-L1 status outcomes, PFS, ORR, DOR, and pharmacokinetics (PK) [30]. MYSTIC is a phase 3 trial that will evaluate durvalumab in combination with tremelimumab and durvalumab monotherapy versus standard chemotherapy in treatment-naive, advanced NSCLC patients. Primary endpoint will include OS, and secondary endpoints will include PD-L1 status outcomes, PFS, ORR, DOR, and PK [31].

\section{Adjuvant and neoadjuvant NSCLC}

The role of PD-1/PD-L1 inhibition has yet to be established in early stage NSCLC. As the cure rates for resected lung cancer still ranges between 40 and $70 \%$ depending on stage, there is clearly a need for improved adjuvant therapy. Pembrolizumab is being evaluated as adjuvant therapy in PD-L1 positive NSCLC patients. "Pembrolizumab (MK-3475) Versus Placebo for Patients With Early Stage
NSCLC After Resection and Completion of Standard Adjuvant Therapy" (PEARLS) trial, an international (European Thoracic Oncology Platform/EORTC-ETOP), phase 3, triple-blinded, placebo-controlled, randomized (1:1) study evaluating pembrolizumab after surgery and standard chemotherapy with a primary endpoint of DFS is currently underway [32]. SAKK $16 / 14$ is a phase 2, multicenter, single-arm trial evaluating durvalumab in the perioperative setting along with standard chemotherapy in resectable NSCLC regardless of histology and PD-L1 expression. Patients will continue the treatment following surgical resection. The primary endpoint is event-free survival at 12 months, and secondary endpoints include OS, ORR, down-staging, complete resection, recurrence pattern, and toxicity [33]. In addition, nivolumab is being evaluated in the neoadjuvant setting in early NSCLC. After surgical resection, standard adjuvant therapy is planned with a primary endpoint of safety and exploratory endpoints of pathologic response, tumor markers by flow cytometry, and immunohistochemistry (IHC). Remarkably, two of the first three patients demonstrated major pathologic and radiographic response and one complete response in a squamous tumor that had a brisk $\mathrm{T}$ cell response [34] (Table 3). 


\section{Small cell lung cancer}

Small cell lung cancer (SCLC) is noted to have a high somatic mutation burden, and association with tobacco use, making it a potential target for checkpoint immunotherapy. Furthermore, PD-L1 (7.3\%), B7-H3 (64.9\%), and B7-H4 (2.6\%) are present in SCLC suggesting that immunotherapy agents alone or in combination may be effective in a subset of these patients [35].

Ipilimumab (10 $\mathrm{mg} / \mathrm{kg}$ every 3 weeks) versus placebo was examined in combination with standard first-line chemotherapy in extensive stage SCLC in a large phase 3 trial $(n=1,132)$ (NCT01450761). Patients received four cycles of combination therapy followed by maintenance ipilimumab versus placebo every 12 weeks. The primary endpoint was OS, and median OS was 11.0 months versus 10.9 months $(\mathrm{HR}=0.94,95 \% \mathrm{CI}, 0.81-1.09, p=$ 0.3775 ) for ipilimumab combination therapy versus placebo therapy. Median PFS was 4.6 versus 4.4 months $(\mathrm{HR}=0.85,95 \% \mathrm{CI}, 0.75-0.97)$. Rate of discontinuation was higher with the ipilimumab arm at $18 \%$ and five treatment-related deaths versus $2 \%$ and two treatmentrelated deaths with the placebo arm. The ipilimumab arm had more frequent episodes of diarrhea, rash, and colitis [36].

CheckMate 032 was a phase $1 / 2$, open-label, multicenter study evaluating nivolumab monotherapy along with nivolumab in combination with ipilimumab for pretreated, extensive SCLC. ORR was $10 \%$ in the nivolumab $3 \mathrm{mg} / \mathrm{kg}$ (nivo3) arm, 33\% in the nivolumab $1 \mathrm{mg} / \mathrm{kg}$ plus ipilimumab $1 \mathrm{mg} / \mathrm{kg}$ (nivo1 + ipi1) arm, $23 \%$ in the nivo1 + ipi3 arm, and $19 \%$ in the nivo3 + ipi1 arm. Grade 3-4 TrAEs occurred at a rate of $13 \%$ with nivo3, $30 \%$ with nivo1 + ipi3, and $19 \%$ with nivo3 + ipi1. No patients treated with nivo1 + ipi1 had grade 3-4 TrAEs. The most common grade 3-4 TrAEs included elevations in lipase and diarrhea. Two patients treated with nivo1 + ipi3 died from grade 5
TrAEs of myasthenia gravis and worsening renal failure while one patient treated with nivo $3+$ ipil died from treatment-related pneumonitis [37]. This study suggested that immunotherapy may be effective in a subset of SCLC patients.

CheckMate 331 is an ongoing phase 3 trial evaluating nivolumab monotherapy for pretreated, advanced SCLC. To date, durable responses have been seen regardless of PD-L1 expression. The primary endpoint will include OS, and secondary endpoints will include PFS, ORR, and safety [36]. CheckMate 451 is a phase 3, randomized, double-blind study evaluating nivolumab monotherapy or in combination with ipilimumab versus placebo as maintenance therapy after platinum-based, first-line chemotherapy (PT-DC) in advanced SCLC. Primary endpoints include OS and PFS. This trial will aim to accrue estimated 810 patients [38].

KEYNOTE-028 is an ongoing phase $1 \mathrm{~b}$ study evaluating pembrolizumab for patients with pretreated, advanced, PD-L1+ SCLC. Pembrolizumab $10 \mathrm{mg} / \mathrm{kg}$ will be given every 2 weeks for up to 2 years or until progression or toxicity. Primary endpoints will include safety and response. Of the initial 16 patients evaluated, 53\% developed TrAEs with only $1 / 16$ patients that developed grade 3 toxicity. Twenty-five percent of the patients had a partial response, and 7\% had stable disease with 37\% of patients with progressive disease. Thirty-one percent of the patients were not evaluated at the time of analysis. Responses were found to be durable for 16+ weeks [39].

In summary, further evaluation will be necessary to establish the role of checkpoint inhibition immunotherapy in SCLC; however, initial combination studies appear promising (see Table 4).

\section{Malignant mesothelioma}

Malignant mesothelioma is a deadly malignancy leading to the deaths of 2497 people in the USA in 2013. More

Table 4 Selected immunotherapy trials in advanced SCLC

\begin{tabular}{|c|c|c|c|c|c|c|c|c|c|}
\hline Trial name & Phase & Therapy & $\mathrm{mOS}$ & 1-year OS & DOR & mPFS & 1-year PFS & mORR (\%) & Ref \\
\hline \multirow[t]{2}{*}{ NCT01450761 } & \multirow[t]{2}{*}{3} & Ipilimumab & 11 & $N R$ & $N R$ & 4.6 & $N R$ & $N R$ & \multirow[t]{2}{*}{ [61] } \\
\hline & & PT-DC & 10.9 & $N R$ & $N R$ & 4.4 & $N R$ & $N R$ & \\
\hline \multirow[t]{4}{*}{ CheckMate 032} & \multirow[t]{4}{*}{$1 / 2$} & NIVO3 & $N R$ & $N R$ & $N R$ & $N R$ & $N R$ & 10 & \multirow[t]{4}{*}[37]{} \\
\hline & & NIVO1 + IPI1 & $N R$ & $N R$ & NR & NR & $N R$ & 33 & \\
\hline & & NIVO1 + IPI3 & NR & $N R$ & $N R$ & $N R$ & $N R$ & 23 & \\
\hline & & NIVO3 + IPI1 & $N R$ & $N R$ & $N R$ & $N R$ & $N R$ & 19 & \\
\hline Ongoing trial name & Phase & Therapy & Setting & \multicolumn{6}{|c|}{ Endpoints (starting with primary) } \\
\hline CheckMate 331 & 3 & NIVO & Advanced SCLC & \multicolumn{5}{|c|}{ OS, PFS, ORR } & [36] \\
\hline CheckMate 451 & 3 & NIVO versus NIVO + IPI & Advanced SCLC & \multicolumn{5}{|l|}{ OS, PFS } & [38] \\
\hline KEYNOTE-028 & $1 b$ & PEMBROQ2W & Advanced SCLC & \multicolumn{5}{|c|}{ ORR, PFS, OS, DOR } & [39] \\
\hline IMpower 133 & 3 & PT-DC +/-ATEZO & Advanced SCLC & \multicolumn{5}{|c|}{ OS, PFS, DOR, safety } & [62] \\
\hline
\end{tabular}


than $80 \%$ of patients have clear asbestos exposure as the etiology. Five-year survival rates are estimated to be as low as $8 \%$. Treatment typically involves surgery, radiation, and chemotherapy, but immunotherapy shows early but promising results [40]. A recent study which evaluated 170 malignant pleural mesotheliomas with IHC, ISH, and next generation and sanger sequencing demonstrated that significant fraction of tumors were positive for PD-1 and PDL1 expression [41]. As described below, several completed and ongoing trials are looking at the efficacy of immunotherapy in mesothelioma.

Tremelimumab (CTLA-4 inhibitor) was evaluated in a phase 2 trial (DETERMINE) versus placebo in pretreated, malignant mesothelioma. Its primary endpoint was OS, and secondary endpoints included PFS, ORR, DCR, DOR, and safety. Unfortunately, there was no difference in OS between tremelimumab and placebo at 7.7 versus 7.3 months $(\mathrm{HR}=0.92,95 \% \mathrm{CI}, 0.76-1.12, p=$ 0.408) [42].

Avelumab, a PD-L1 inhibitor, is being evaluated in a phase $1 \mathrm{~b}$ study (JAVELIN) in pretreated, unresectable malignant mesothelioma patients. At interim analysis, 53 patients were evaluated at a median of 46 weeks. PFS rate at 24 weeks was $38.4 \%$ (95\% CI, 23.3-53.4). 35.9\% of the tumors were PD-L1+, and ORR was $14.3 \%$ in PD$\mathrm{L} 1+$ tumors versus $8.0 \%$ in PD-L1- tumors. Median PFS was 17.1 weeks $(95 \% \mathrm{CI}, 5.4+)$ in PD-L1+ tumors versus 7.4 weeks (95\% CI, 6.0-30.1) in PD-L1- tumors [43].

NIBIT-MESO1 is a phase 2 study that will evaluate durvalumab $20 \mathrm{mg} / \mathrm{kg}$ every 4 weeks in combination with tremelimumab $1 \mathrm{mg} / \mathrm{kg}$ every 4 weeks in first-line and second-line therapy for malignant pleural and peritoneal mesothelioma. Patients will be evaluated with a primary endpoint of irORR, and secondary endpoints include irDCR, irPFS, OS, DCR, PFS, and safety [44]. In summary, immunotherapy as a novel treatment modality for mesothelioma is promising but still early (see Table 5 ).

\section{Novel combinations}

Only a subset of NSCLC patients respond to checkpoint blockade therapy; therefore, new combinations of therapy have been proposed to increase response rates and efficacy. Based on preclinical studies, several potential targets appear to be good candidates for inhibition. CD3 and CD8 are cell surface markers typically seen with $\mathrm{T}$ cells. PD-1 interacts with both PD-L1 and PD-L2 to downregulate $T$ cell activation. CTLA-4 binds to CD80 or CD86 on APCs to decrease antigen presentation. IDO-1 is an enzyme that can deplete tryptophan leading to the decreased growth of T cells. B7-H4 is a surface protein that can negatively regulate $\mathrm{T}$ cells when interacting with them (Fig. 1). A number of novel combinations are currently being examined.

Increased levels of indoleamine 2,3-dioxygenase (IDO) can serve as a tumor derived immunosuppression mechanism via the increased metabolism of tryptophan to kynurenine. In addition, stage III NSCLC patients were evaluated before and after chemoradiation and patients with an elevated kynurenine/tryptophan ratio had worse OS (HR 1.25, 95\% CI 1.01-1.56, $p=0.04$ ) suggesting that IDO activity is a possible immune escape mechanism [45]. Therefore, IDO has been and continues to be evaluated as a potential target. The IDO inhibitor, indoximod, is being evaluated in a phase 1 setting alone and has been shown to be safe and efficacious in pretreated, advanced solid tumors. Out of the 48 patients on study, 10 patients had NSCLC. Hypophysitis was the main toxicity that was noted [46]. Indoximod is also being evaluated in combination with checkpoint inhibition therapy including nivolumab, pembrolizumab, and ipilimumab. The early phase $1 / 2$ study will evaluate ORR in advanced melanoma. This combination is also being evaluated in other disease states along with NSCLC [47].

Nivolumab is being evaluated with an allogeneic whole-cell vaccine called viagenpumatucel-L or HS-110. This vaccine will be selected for adenocarcinoma tumor antigens and transfected to secrete gp96-Ig to the patient's antigen presenting cells (APCs) leading to increased cytotoxic CD8+ TILs. Pretreated, advanced NSCLC patients will be stratified according to TIL findings (low TIL $\leq 10 \%$ CD $8+$ T cells versus high TIL $>10 \%$ CD8+ T cells). The primary endpoints will include safety and then ORR with plans for biopsies at baseline and week 10 along with PD-L1 staining [48].

Table 5 Selected immunotherapy trials in malignant mesothelioma

\begin{tabular}{|c|c|c|c|c|c|c|c|c|c|}
\hline Trial name & Phase & Therapy & mOS & 1-year OS & DOR & mPFS (weeks) & 1-year PFS & mORR (\%) & Ref \\
\hline \multirow[t]{2}{*}{ DETERMINE } & $2 b$ & Tremelimumab & 7.7 & $N R$ & NR & NR & NR & $N R$ & [42] \\
\hline & & Placebo & 7.3 & NR & NR & NR & NR & NR & \\
\hline \multirow[t]{2}{*}{ JAVELIN } & 1 & Avelumab PD-L1+ & NR & NR & NR & 17.1 & NR & 14.3 & [43] \\
\hline & & Avelumab PD-L1- & NR & NR & NR & 7.4 & NR & 8.0 & \\
\hline Ongoing trial name & Phase & Therapy & Setting & \multicolumn{6}{|c|}{ Endpoints (starting with primary) } \\
\hline NIBIT-MESO-1 & 2 & Durvalumab + tremelimumab & $\begin{array}{l}\text { Unresectable malignant } \\
\text { mesothelioma }\end{array}$ & \multicolumn{5}{|c|}{ ORR, DCR, PFS, OS (by PD-L1\%), and safety. } & [44] \\
\hline
\end{tabular}


Pembrolizumab is being evaluated in combination with concurrent chemoradiation for stage III NSCLC. The primary endpoint is distant recurrence, and secondary endpoints include PFS, OS, and toxicity. During early evaluation, only one grade 3 urinary toxicity was reported [49].

Phase $1 \mathrm{~b} / 2$ trials are evaluating pembrolizumab in combination with entinostat (a histone deacetylase inhibitor) in pretreated, advanced NSCLC. In animal models, blocking histone deacetylation with entinostat has been shown to decrease the activity of Tregs and suppressor $\mathrm{T}$ cells leading to increased $\mathrm{T}$ cell activation [50]. Early results show one grade 3 elevation in alkaline phosphatase and bilirubin concerning for mild hepatitis, and stable disease was seen in three out of six evaluated patients [51].

Pembrolizumab is being evaluated in early phase trials in combination with oral azacitadine in pretreated, advanced NSCLC. Hypomethylating agents such as azacitadine can lead to epigenetic changes that are proposed to lead to increased tumor immunogenicity and more responsive to immunotherapy. Patients will be stratified according to histology, with a primary endpoint of PFS, and secondary endpoints including DCR, OS, ORR, safety, and pharmacokinetics. Further exploratory endpoints will include PD-L1 expression, TILs, gene expression, and DNA methylation analysis [52].

IPI-549, a PI3K-gamma inhibitor, is under evaluation in multiple tumor types, including NSCLC, as monotherapy and in combination with pembrolizumab. PI3Kgamma has been shown to increase the immunosuppressive effects of myeloid cells in the tumor microenvironment, and inhibition of this molecule has shown decreased tumor growth in preclinical studies. This effect has been increased when IPI-549 was used in combination with checkpoint inhibition. A phase $1 / 1 \mathrm{~b}$ study will help determine the MTD, PK, and safety and will further assess the efficacy in multiple tumor types including NSCLC [53].

Durvalumab is being evaluated in combination with bavituximab in pretreated, advanced NSCLC patients. Bavituximab is an inhibitor of phosphatidylserine which is an immunosuppressive molecule expressed on tumor cells and exosomes in the tumor microenvironment. Bavituximab has shown improvement in median OS in nonsquamous, pretreated, advanced NSCLC patients with combination with docetaxel over control (11.7 versus 7.3 months). Early phase trials will evaluate bavituximab in combination with durvalumab until progression or toxicity, with a primary endpoint of ORR, and secondary endpoints of PFS, OS, and safety [54].

\section{Resistance mechanisms}

Duration of response to PD-1/PD-L1 inhibition is notably longer compared to cytotoxic regimens. However, some patients eventually progress and the etiology of resistance is an active area of research. Interestingly, small studies utilizing whole-exome sequencing in patients who initially responded to PD-1 checkpoint inhibition and then progressed found mutations involving interferon pathway genes. Loss of function mutations and truncating mutations were seen in JAK1, JAK2, and B2M proteins associated with the interferon signaling pathways. Further studies will be needed to verify these resistance mechanisms to checkpoint inhibition in lung cancer, but these findings suggest future therapeutic targets for patients who progress on checkpoint inhibition [55].

Increased Tregs and DCs in the tumor environment may be responsible for acquired resistance and provide another therapeutic target to prevent or overcome resistance. Tregs can be identified with the cell surface markers Foxp3, CD25, CD357, lymphocyte-activation gene 3 (LAG3), CTLA-4, and low CD127. Forkhead box protein 3 (Foxp3) are crucial in the immunosuppressive activity of suppressor $\mathrm{T}$ cells or Tregs within the lung cancer tumor microenvironment (TME). Foxp3 is a transcription factor that is upregulated in TILs and tumor cells and coveys a negative prognostic factor in the lung cancer and maybe a future target for resistant tumors. LAG3 is also a co-inhibitory molecule on TILs, Tregs, DCs, and NK cells that dampens T cell activation via its binding to MHC II receptors, making it another possible therapeutic target after resistance. $\mathrm{T}$ cell immunoglobulin and mucin domain-3-containing molecule 3 (TIM3) is a cell surface protein typically seen on DCs that interact with Galectin-9 on T cells leading to inhibition of the $\mathrm{T}$ cell response. TIM-3 expression can be seen on TILs, and its interaction with galectin-9 on Tregs or tumor cells can lead to T cell inhibition (Fig. 1). Increased TIM-3 expression has been seen as a marker of poor prognosis but may also provide an alternative checkpoint target for therapy after PD-1 failure [56, 57].

\section{Conclusions}

Checkpoint blockade immunotherapy has revolutionized the treatment of lung cancer. PD-1/PD-L1 inhibitors such as nivolumab and pembrolizumab have shown improved efficacy and longer duration of response compared to standard-of-care chemotherapy (docetaxel). Treatment with nivolumab provided benefit in patients with advanced squamous cell carcinoma regardless of PD-L1 status while the efficacy of nivolumab is more pronounced in the PD-L1 positive, nonsquamous population compared to the PD-L1 negative, nonsquamous population. Pembrolizumab shows benefit in conjunction with its companion diagnostic for PD-L1 positive patients regardless of histology [58]. Atezolizumab is a PD-L1 inhibitor but has shown similar efficacy as its predecessors and benefit over standard-of-care chemotherapy in the pretreated setting. 
Given the promising findings in the pretreated setting, checkpoint blockade therapy is being evaluated in the first-line setting also. The phase III study of nivolumab did not meet its primary endpoint of PFS while the study of pembrolizumab did. This is possibly because of the more stringent PD-L1 expression cutoff in the pembrolizumab trial (50\%) compared to the nivolumab trial (5\%). This has led to the FDA approval of pembrolizumab in the first-line setting for tumors with $\geq 50 \%$ PD-L1 positivity and established a new standard of care. Anti-PDL1 agents are also being tested as monotherapy as well. While ipilimumab alone has not shown significant benefit, combination with nivolumab is still undergoing evaluation in the treatment-naïve setting but is promising based on the preliminary data. Combination therapy with pembrolizumab or atezolizumab and chemotherapy is still early, and finding the best histology and PD-L1 expression population will be beneficial. Furthermore, these agents are now being examined in the neoadjuvant and adjuvant settings where they may lead to a significant increase in lung cancer survival.

The benefit of checkpoint inhibition does not appear to be limited to NSCLC as promising results have been observed in extensive stage SCLC with nivolumab monotherapy and in combination with ipilimumab. Additional studies with anti PD-1/PD-L1 will define the true potential of these agents in SCLC. Trials for checkpoint blockade in malignant mesothelioma are ongoing but include therapies such as nivolumab, pembrolizumab, tremelimumab, avelumab, and durvalumab mostly in the pretreated setting.

Newer combinations are also being evaluated such as pembrolizumab plus ipilimumab in the pretreated NSCLC population or durvalumab plus tremelimumab in the treatment-naïve population. IDO inhibition with indoximod will be evaluated in various treatment settings alone and in combination with PD-1/PD-L1 inhibition. Pembrolizumab will be evaluation in the stage III setting with chemoradiation along with azacitadine, a PIK3-gamma inhibitor and an HDAC inhibitor in the pretreated, advanced population. Nivolumab will be evaluated in combination with a whole-cell vaccine, and durvalumab will be evaluated in combination with a phosphatidylserine inhibitor in the pretreated, advanced population.

The future for these agents as monotherapy and in combination with novel agents appears bright in lung cancer. However, there are many unanswered questions in regard to the proper use of the agents including the duration of use for these agents [59], which biomarker(s) will be predictive for response or toxicity, what leads to acquired resistance to these agent,s and which combinations will be the most effective in overcoming and preventing resistance? Over the next several years, it is likely that significant progress will be made in addressing many of these questions.

\section{Abbreviations}

APC: Antigen presenting cells; ATEZO: Atezolizumab; CTLA-4: Cytotoxic T-lymphocyte-associated protein 4; DC: Dendritic cells; DOC: Docetaxel; DOR: Duration of response; HR: Hazard ratio; IHC: Immunohistochemistry; IPI: Ipilimumab; NIVO: Nivolumab; NONSQ: Nonsquamous; NSCLC: Non-small cell lung cancer; ORR: Overall response rate; OS: Overall survival; PD-1: Programmed death 1; PD-L1: Programmed death ligand 1; PEMBRO: Pembrolizumab; PFS: Progression-free survival; PK: Pharmacokinetics; SCLC: Small cell lung cancer; SQ: Squamous; TIL: Tumor-infiltrating lymphocyte; TrAE: Treatment-related adverse event; Treg: Regulatory T cell

\section{Acknowledgements}

The authors would like to thank the University of Pittsburgh Cancer Institute for their support.

\section{Funding}

No funding was received for this manuscript

\section{Availability of data and materials}

This is a review article, and our supporting data was obtained from the referenced publications.

\section{Authors' contributions}

AS prepared the initial manuscript draft, figure, and tables. TFB contributed essential information, suggestions, and organization and critically reviewed the literature and manuscript. Both authors read and approved the final manuscript.

\section{Competing interests}

T.F.B. has served on an ad hoc steering committee for Regeneron Pharmaceuticals, Inc. The other author declares they he has no competing interests.

\section{Consent for publication}

Not applicable.

\section{Ethics approval and consent to participate} Not applicable.

\section{Publisher's Note}

Springer Nature remains neutral with regard to jurisdictional claims in published maps and institutional affiliations.

Received: 31 December 2016 Accepted: 29 March 2017

Published online: 24 April 2017

\section{References}

1. Siegel RL, Miller KD, Jemal A. Cancer statistics, 2016. CA Cancer J Clin. 2016; 66(1):7-30

2. Dholaria B, Hammond W, Shreders A, Lou Y. Emerging therapeutic agents for lung cancer. J Hematol Oncol. 2016;9(1):138.

3. Pardoll DM. The blockade of immune checkpoints in cancer immunotherapy. Nat Rev Cancer. 2012;12(4):252-64.

4. Lynch TJ, Bondarenko I, Luft A, Serwatowski P, Barlesi F, Chacko R, Sebastian M, Neal J, Lu H, Cuillerot JM, Reck M. Ipilimumab in combination with paclitaxel and carboplatin as first-line treatment in stage IIIB/IV non-smallcell lung cancer: results from a randomized, double-blind, multicenter phase II study. J Clin Oncol. 2012;30(17):2046-54.

5. Konishi J, Yamazaki K, Azuma M, Kinoshita I, Dosaka-Akita H, Nishimura M. B7-H1 expression on non-small cell lung cancer cells and its relationship with tumor-infiltrating lymphocytes and their PD-1 expression. Clin Cancer Res. 2004;10(15):5094-100.

6. Topalian SL, Hodi FS, Brahmer JR, Gettinger SN, Smith DC, McDermott DF, Powderly JD, Carvajal RD, Sosman JA, Atkins MB. Safety, activity, and immune correlates of anti-PD-1 antibody in cancer. N Engl J Med. 2012; 366(26):2443-54.

7. Hamid O, Robert C, Daud A, Hodi FS, Hwu WJ, Kefford R, Wolchok JD, Hersey P, Joseph RW, Weber JS, Dronca R, Gangadhar TC, Patnaik A, Zarour H, Joshua AM, Gergich K, Elassaiss-Schaap J, Algazi A, Mateus C, Boasberg P, Tumeh PC, Chmielowski B, Ebbinghaus SW, Li XN, Kang SP, Ribas A. Safety 
and tumor responses with lambrolizumab (anti-PD-1) in melanoma. N Engl J Med. 2013;369(2):134-44.

8. Brahmer JR, Tykodi SS, Chow LQ, Hwu WJ, Topalian SL, Hwu P, Drake CG, Camacho LH, Kauh J, Odunsi K, Pitot HC, Hamid O, Bhatia S, Martins R, Eaton K, Chen S, Salay TM, Alaparthy S, Grosso JF, Korman AJ, Parker SM, Agrawal S, Goldberg SM, Pardoll DM, Gupta A, Wigginton JM. Safety and activity of anti-PD-L1 antibody in patients with advanced cancer. N Engl J Med. 2012:366(26):2455-65.

9. Brahmer J, Reckamp KL, Baas P, Crino L, Eberhardt WE, Poddubskaya E, Antonia S, Pluzanski A, Vokes EE, Holgado E, Waterhouse D, Ready N, Gainor J, Aren Frontera O, Havel L, Steins M, Garassino MC, Aerts JG, Domine M, Paz-Ares L, Reck M, Baudelet C, Harbison CT, Lestini B, Spigel DR. Nivolumab versus docetaxel in advanced squamous-cell non-small-cell lung cancer. $\mathrm{N}$ Engl J Med. 2015;373(2):123-35.

10. Borghaei H, Paz-Ares L, Horn L, Spigel DR, Steins M, Ready NE, Chow LQ, Vokes EE, Felip E, Holgado E, Barlesi F, Kohlhaufl M, Arrieta O, Burgio MA, Fayette J, Lena H, Poddubskaya E, Gerber DE, Gettinger SN, Rudin CM, Rizvi N, Crino L, Blumenschein Jr GR, Antonia SJ, Dorange C, Harbison CT, Graf Finckenstein F, Brahmer JR. Nivolumab versus docetaxel in advanced nonsquamous non-small-cell lung cancer. N Engl J Med. 2015;373(17): 1627-39.

11. Garon EB, Rizvi NA, Hui R, Leighl N, Balmanoukian AS, Eder JP, Patnaik A, Aggarwal C, Gubens M, Horn L, Carcereny E, Ahn MJ, Felip E, Lee JS, Hellmann MD, Hamid O, Goldman JW, Soria JC, Dolled-Filhart M, Rutledge RZ, Zhang J, Lunceford JK, Rangwala R, Lubiniecki GM, Roach C, Emancipator K, Gandhi L. Pembrolizumab for the treatment of non-smallcell lung cancer. N Engl J Med. 2015;372(21):2018-28.

12. Herbst RS, Baas P, Kim D-W, Felip E, Pérez-Gracia JL, Han J-Y, Molina J, Kim J$\mathrm{H}$, Arvis CD, Ahn M-J. Pembrolizumab versus docetaxel for previously treated, PD-L1-positive, advanced non-small-cell lung cancer (KEYNOTE-010): a randomised controlled trial. Lancet. 2016;387(10027):1540-50.

13. Fehrenbacher L, Spira A, Ballinger M, Kowanetz M, Vansteenkiste J, Mazieres J, Park K, Smith D, Artal-Cortes A, Lewanski C, Braiteh F, Waterkamp D, He P, Zou W, Chen DS, Yi J, Sandler A, Rittmeyer A. Atezolizumab versus docetaxel for patients with previously treated non-small-cell lung cancer (POPLAR): a multicentre, open-label, phase 2 randomised controlled trial. Lancet. 2016; 387(10030):1837-46.

14. Smith DA, Vansteenkiste JF, Fehrenbacher L, Park K, Mazieres J, Rittmeyer A, Artal-Cortes A, Lewanski CR, Braiteh FS, Yi J, He P, Zou W, Kowanetz M, Waterkamp D, Ballinger M, Chen DS, Sandler A, Spira Al. Updated survival and biomarker analyses of a randomized phase II study of atezolizumab vs docetaxel in 2L/3L NSCLC (POPLAR). ASCO Meeting Abstracts. 2016;34(15_ suppl):9028.

15. Rittmeyer A, Barlesi F, Waterkamp D, Park K, Ciardiello F, von Pawel J, Gadgeel SM, Hida T, Kowalski DM, Dols MC, Cortinovis DL, Leach J, Polikoff J, Barrios C, Kabbinavar F, Frontera OA, De Marinis F, Turna H, Lee JS, Ballinger M, Kowanetz M, He P, Chen DS, Sandler A, Gandara DR. Atezolizumab versus docetaxel in patients with previously treated nonsmall-cell lung cancer (OAK): a phase 3, open-label, multicentre randomised controlled trial. Lancet. 2017;389(10066):255-65.

16. Herbst RS, Gandara DR, Hirsch FR, Redman MW, LeBlanc M, Mack PC, Schwartz LH, Vokes E, Ramalingam SS, Bradley JD, Sparks D, Zhou Y, Miwa C, Miller VA, Yelensky R, Li Y, Allen JD, Sigal EV, Wholley D, Sigman CC, Blumenthal GM, Malik S, Kelloff GJ, Abrams JS, Blanke CD, Papadimitrakopoulou VA. Lung Master Protocol (Lung-MAP)—a biomarkerdriven protocol for accelerating development of therapies for squamous cell lung cancer: SWOG S1400. Clin Cancer Res. 2015;21(7):1514-24.

17. Gubens MA, Sequist LV, Stevenson J, Powell SF, Villaruz LC, Gadgeel SM, Langer CJ, Patnaik A, Borghaei H, Jalal SI, Fiore J, Ge JY, Raftopoulos H, Gandhi L. Phase I/II study of pembrolizumab (pembro) plus ipilimumab (ipi) as second-line therapy for NSCLC: KEYNOTE-021 cohorts D and H. ASCO Meeting Abstracts. 2016;34(15_suppl):9027.

18. Gettinger S, Rizvi NA, Chow LQ, Borghaei H, Brahmer J, Ready N, Gerber DE, Shepherd FA, Antonia S, Goldman JW. Nivolumab monotherapy for first-line treatment of advanced non-small-cell lung cancer. J Clin Oncol 2016:34(25): JCO669929.

19. Rizvi NA, Hellmann MD, Brahmer JR, Juergens RA, Borghaei H, Gettinger $S$, Chow LQ, Gerber DE, Laurie SA, Goldman JW, Shepherd FA, Chen AC, Shen $Y$, Nathan FE, Harbison CT, Antonia S. Nivolumab in combination with platinum-based doublet chemotherapy for first-line treatment of advanced non-small-cell lung cancer. J Clin Oncol. 2016;34(25):2969-79.
20. ASCO-post: nivolumab did not meet primary endpoint of progression-free survival in NSCLC in CheckMate-026 trial. In. http://www.ascopost.com/ News/43820; 2016. Accessed 1 Dec 2016.

21. Reck M, Rodriguez-Abreu D, Robinson AG, Hui R, Csoszi T, Fulop A, Gottfried M, Peled N, Tafreshi A, Cuffe S, O'Brien M, Rao S, Hotta K, Leiby MA, Lubiniecki GM, Shentu Y, Rangwala R, Brahmer JR. Pembrolizumab versus chemotherapy for PD-L1-positive non-small-cell lung cancer. N Engl J Med. 2016;375(19):1823-33.

22. Bristo-Myers-Squibb: Opdivo ${ }^{\oplus}$ (nivolumab) and Yervoy ${ }^{\oplus}$ (ipilimumab) combination regimen shows clinically meaningful responses in first-line advanced non-small cell lung cancer, In Updated Phase 1b Study CheckMate -012. In. http://www.businesswire.com/news/home/ 20160604005075/en/; 2016. Accessed 1 Dec 2016.

23. Hellmann M, Ramalingam S, Reck M, O'Byrne K, Paz-Ares L, Harbison CT, Bhagavatheeswaran P, Nathan F, Brahmer J. An open label randomized Phase III trial of nivolumab or nivolumab plus ipilimumab vs platinum doublet chemotherapy (PT-DC) in patients with chemotherapy-naïve stage IV or recurrent non-small cell lung cancer (NSCLC)(CheckMate 227). J Immunother Cancer. 2015;3(2):1.

24. Hall RD, Gadgeel SM, Garon EB, Bria E, Reck M, Vida J, Zhou H, Raftopoulos H, Gandhi L. Phase 3 study of platinum-based chemotherapy with or without pembrolizumab for first-line metastatic, nonsquamous non-small cell lung carcinoma (NSCLC): KEYNOTE-189. ASCO Meeting Abstracts. 2016; 34(15_suppl):TPS9104.

25. NCT02366143. A phase III study of MPDL3280A (anti-PD-L1 antibody) in combination with carboplatin + paclitaxel with or without bevacizumab in patients with stage IV non-squamous non-small cell lung cancer [IMpower 150] [www.clinicaltrials.gov]. Accessed 1 Dec 2016.

26. NCT02367781. A phase III study of MPDL3280A (anti-PD-L1 antibody) in combination with carboplatin + nab-paclitaxel in patients with nonsquamous non-small cell lung cancer [IMpower 130] [www.clinicaltrials.gov]. Accessed 1 Dec 2016.

27. NCT02367794. A study of atezolizumab in combination with carboplatin + paclitaxel or carboplatin + nab-paclitaxel compared with carboplatin + nabpaclitaxel in participants with stage IV squamous non-small cell lung cancer (NSCLC) [IMpower 131] [www.clinicaltrials.gov]. Accessed 1 Dec 2016.

28. NCT02409342. A study of atezolizumab (MPDL3280A) compared with cisplatin or carboplatin + pemetrexed in patients with stage IV nonsquamous non-small cell lung cancer (NSCLC) [IMpower110] [www. clinicaltrials.gov]. Accessed 1 Dec 2016.

29. NCT02409355. A study of atezolizumab (MPDL3280A) compared with gemcitabine + cisplatin or carboplatin in patients with stage IV squamous non-small cell lung cancer [IMpower111] [www.clinicaltrials.gov]. Accessed 1 Dec 2016.

30. NCT02542293. Study of 1st line therapy study of MEDI4736 with tremelimumab versus SoC in non small-cell lung cancer (NSCLC) (NEPTUNE). [www.clinicaltrials.gov]. Accessed 1 Dec 2016.

31. NCT02453282. Phase III open label first line therapy study of MEDI 4736 (Durvalumab) with or without tremelimumab versus SOC in non small-cell lung cancer (NSCLC). [www.clinicaltrials.gov]. Accessed 1 Dec 2016.

32. O'Brien MER, Hasan B, Dafni U, Menis J, Peters S, De Waele M, Stahel RA, Van Schil P, Coukos G, Lantuejoul S, Kerr KM, Melero I, Besse B, Paz-Ares LG. EORTC-ETOP randomized, phase 3 trial with anti-PD-1 monoclonal antibody pembrolizumab versus placebo for patients with early stage non-small cell lung cancer (NSCLC) after resection and standard adjuvant chemotherapy: PEARLS (NCT02504372). ASCO Meeting Abstracts. 2016;34(15_suppl):TPS8571.

33. Rothschild S, Zippelius A, Savic S, Gonzalez M, Weder W, Xyrafas A, Rusterholz C, Pless M. SAKK 16/14: anti-PD-L1 antibody durvalumab (MEDI4736) in addition to neoadjuvant chemotherapy in patients with stage IIIA(N2) non-small cell lung cancer (NSCLC) — a multicenter single-arm phase II trial. ASCO Meeting Abstracts. 2016;34(15_suppl):TPS8573.

34. Forde PM, Smith K, Chaft JE, Hellmann MD, Merghoub T, Wolchok JD, Yang SC, Battafarano RJ, Gabrielson E, Georgiades C, Verde F, Rosner GL, Anagnostou V, Velculescu VE, Topalian SL, Pardoll DM, Brahmer JR. Neoadjuvant anti-PD1, nivolumab, in early stage resectable non-small-cell lung cancer. ASCO Meeting Abstracts. 2016;34(15 suppl):e20005.

35. Schalper KA, Carvajal-Hausdorf DE, McLaughlin JF, Altan M, Chiang AC, Velcheti V, Kaftan E, Zhang J, Lu L, Rimm DL, Han B, Lu H, Zhao H, Herbst RS. Objective measurement and significance of PD-L1, B7-H3, B7-H4 and TILs in small cell lung cancer (SCLC). ASCO Meeting Abstracts. 2016;34(15 suppl):8566

36. Reck M, Luft A, Szczesna A, Havel L, Kim SW, Akerley W, Pietanza MC, Wu YL, Zielinski C, Thomas M, Felip E, Gold K, Horn L, Aerts J, Nakagawa K, Lorigan 
P, Pieters A, Kong Sanchez T, Fairchild J, Spigel D: Phase III randomized trial of ipilimumab plus etoposide and platinum versus placebo plus etoposide and platinum in extensive-stage small-cell lung cancer. J Clin Oncol 2016.

37. Antonia SJ, Lopez-Martin JA, Bendell J, Ott PA, Taylor M, Eder JP, Jager D, Pietanza MC, Le DT, de Braud F, Morse MA, Ascierto PA, Horn L, Amin A, Pillai RN, Evans J, Chau I, Bono P, Atmaca A, Sharma P, Harbison CT, Lin CS, Christensen O, Calvo E. Nivolumab alone and nivolumab plus ipilimumab in recurrent small-cell lung cancer (CheckMate 032): a multicentre, open-label, phase 1/2 trial. Lancet Oncol. 2016;17(7):883-95.

38. Ready N, Owonikoko TK, Postmus PE, Reck M, Peters S, Pieters A, Selvaggi G, Fairchild JP, Govindan R. CheckMate 451: a randomized, double-blind, phase III trial of nivolumab (nivo), nivo plus ipilimumab (ipi), or placebo as maintenance therapy in patients (pts) with extensive-stage disease small cell lung cancer (ED-SCLC) after first-line platinum-based doublet chemotherapy (PT-DC). ASCO Meeting Abstracts. 2016;34(15_suppl):TPS8579.

39. Ott PA, Fernandez MEE, Hiret S, Kim D-W, Moss RA, Winser T, Yuan S, Cheng JD, Piperdi B, Mehnert JM: Pembrolizumab (MK-3475) in patients (pts) with extensive-stage small cell lung cancer (SCLC): preliminary safety and efficacy results from KEYNOTE-028. In: ASCO Annual Meeting Proceedings. Alexandria: J Clin Oncol; 2015. 7502.

40. Malignant mesothelioma [http://www.cancer.org/acs/groups/cid/ documents/webcontent/003119-pdf.pdf]. Accessed 1 Dec 2016.

41. Arguello D, El-Deiry WS, Zhou L, Reddy SS, Scott WJ, Abass AE, Kaiser LR, Hallman MA, Sawhney R, Jeong W, Kim ES, Liu SV, Ma PC, Gatalica Z, Reddy SK, Borghaei H, Testa JR. Incidence of ALK, CKIT, CMET, EGFR, PD1/PD-L1, and JAK3 alterations in 170 malignant pleural mesotheliomas (MPM) and 102 peritoneal mesotheliomas. ASCO Meeting Abstracts. 2016;34(15_suppl): e20076.

42. Kindler HL, Scherpereel A, Calabro L, Aerts J, Cedres Perez S, Bearz A, Nackaerts K, Fennell DA, Kowalski D, Tsao AS, Taylor P, Grosso F, Antonia SJ, Nowak AK, Ibrahim RA, Taboada M, Puglisi M, Stockman PK, Maio M. Tremelimumab as second- or third-line treatment of unresectable malignant mesothelioma (MM): results from the global, double-blind, placebo-controlled DETERMINE study. ASCO Meeting Abstracts. 2016;34(15_ suppl):8502.

43. Hassan R, Thomas A, Patel MR, Nemunaitis JJ, Bennouna J, Powderly JD, Taylor MH, Dowlati A, Chen F, Leach J, Vaishampayan UN, Verschraegen CF, Delord J-P, Grote HJ, von Heydebreck A, Cuillerot J-M, Gulley UL. Avelumab (MSB0010718C; anti-PD-L1) in patients with advanced unresectable mesothelioma from the JAVELIN solid tumor phase Ib trial: safety, clinical activity, and PD-L1 expression. ASCO Meeting Abstracts. 2016;34(15_suppl):8503.

44. Calabro L, Morra A, Giannarelli D, Annesi D, Bertocci E, Danielli R, Altomonte M, Di Giacomo AM, Maio M. Tremelimumab and durvalumab (MEDI4736) combination for first and second-line treatment of mesothelioma patients: the NIBIT-MESO-1 study. ASCO Meeting Abstracts. 2016;34(15_suppl): TPS8575.

45. Creelan BC, Bepler G, Antonia S, Garrett T, Soliman HH. Indoleamine 2,3dioxygenase activity and clinical outcome following induction chemotherapy and concurrent chemoradiation in stage III non-small cell lung cancer. ASCO Meeting Abstracts. 2011;29(15_suppl):10538.

46. Soliman HH, Minton SE, Han HS, Ismail-Khan R, Neuger A, Khambati F, Noyes D, Lush R, Chiappori AA, Roberts JD. A Phase I study of indoximod in patients with advanced malignancies. Oncotarget. 2016;7(16):22928-38.

47. NCT02073123. Study of IDO inhibitor in combination with checkpoint inhibitors for adult patients with metastatic melanoma. [www.clinicaltrials. gov]. Accessed 1 Dec 2016

48. Morgensztern D, Harb WA, Schalper KA, Price ML, Early B, Schreiber TH. Broadening response rates to PD-1 therapy in advanced lung adenocarcinoma: Viagenpumatucel-I (HS-110) in combination with nivolumab in the ongoing DURGA trial. ASCO Meeting Abstracts. 2016; 34(15_suppl):TPS9102.

49. Durm GA, Kio EA, Fisher WB, Titzer ML, Jabbour S, Breen T, Liu Z, Hanna NH. Phase II trial of consolidation Pembrolizumab following concurrent chemoradiation in patients (pts) with unresectable or inoperable stage III non-small cell lung cancer (NSCLC): initial safety data from HCRN LUN 14179. ASCO Meeting Abstracts. 2016;34(15_suppl):e20025.

50. Ruiz R, Raez LE, Rolfo C. Entinostat (SNDX-275) for the treatment of nonsmall cell lung cancer. Expert Opin Investig Drugs. 2015;24(8):1101-9.

51. Johnson ML, Adjei AA, Ramalingam SS, Janne PA, Dominguez G, Gabrilovich D, Deleon L, Hasapidis JL, Diede SJ, Ordentlich P, Hellmann MD. Preliminary results of ENCORE 601, a phase 1b/2, open-label study of entinostat (ENT) in combination with pembrolizumab (PEMBRO) in patients with non-small cell lung cancer (NSCLC). ASCO Meeting Abstracts. 2016;34(15_suppl):e20659.

52. Levy BP, Giaccone G, Besse B, Begic D, Wu X, Fandi A, Paz-Ares L. A phase II multicenter, randomized, placebo-controlled, double-blind study of CC-486 plus pembrolizumab (pembro) vs pembro plus placebo (PBO) in previously treated patients (pts) with locally advanced/metastatic non-small cell lung cancer (NSCLC). ASCO Meeting Abstracts. 2016;34(15_suppl):TPS9107.

53. Tolcher AW, Hong DS, Sullivan RJ, Mier JW, Shapiro G, Pearllberg J, Brail LH, Kharidia J, Han L, Dansky UIImann C, Stern HM, Wolchok JD. IPI-549-01-A phase 1/1b first in human study of IPI-549, a PI3K-\{gamma\} inhibitor, as monotherapy and in combination with pembrolizumab in subjects with advanced solid tumors. ASCO Meeting Abstracts. 2016;34(15_suppl): TPS3111.

54. Natale RB, Spigel DR, Sanborn RE, Chiappori A, Ramalingam SS, Dragnev KH, Shan J, Stepp L, McCleod M, Waterhouse DM, Gerber DE. PPHM 1501-an open-label, randomized, phase II trial of durvalumab (MEDI4736) with or without bavituximab in patients with previously treated metastatic nonsmall cell lung cancer (NSCLC): Safety report on first 18 patients. ASCO Meeting Abstracts. 2016;34(15_suppl):e14537.

55. Zaretsky JM, Garcia-Diaz A, Shin DS, Escuin-Ordinas H, Hugo W, HuLieskovan S, Torrejon DY, Abril-Rodriguez G, Sandoval S, Barthly L, Saco J, Homet Moreno B, Mezzadra R, Chmielowski B, Ruchalski K, Shintaku IP, Sanchez PJ, Puig-Saus C, Cherry G, Seja E, Kong X, Pang J, Berent-Maoz B, Comin-Anduix B, Graeber TG, Tumeh PC, Schumacher TN, Lo RS, Ribas A. Mutations associated with acquired resistance to PD-1 blockade in melanoma. N Engl J Med. 2016;375(9):819-29.

56. Schneider T, Kimpfler S, Warth A, Schnabel PA, Dienemann H, Schadendorf D, Hoffmann H, Umansky V. Foxp3(+) regulatory T cells and natural killer cells distinctly infiltrate primary tumors and draining lymph nodes in pulmonary adenocarcinoma. J Thorac Oncol. 2011;6(3):432-8.

57. Sundar R, Cho BC, Brahmer JR, Soo RA. Nivolumab in NSCLC: latest evidence and clinical potential. Ther Adv Med Oncol. 2015;7(2):85-96.

58. Ma W, Gilligan BM, Yuan J, Li T. Current status and perspectives in translational biomarker research for PD-1/PD-L1 immune checkpoint blockade therapy. J Hematol Oncol. 2016;9(1):47.

59. Davar D, Socinski MA, Dacic S, Burns TF. Near complete response after single dose of nivolumab in patient with advanced heavily pre-treated KRAS mutant pulmonary adenocarcinoma. Exp Hematol Oncol. 2015;4:34.

60. Socinski M, Creelan B, Horn L, Reck M, Paz-Ares L, Steins M, Felip E, van den Heuvel M, Ciuleanu TE, Badin F, Ready N, Hiltermann TJN, Nair S, Juergens R, Peters S, Minenza E, Geese WJ, Bhagavatheeswaran P, Chen A, Carbone DP. NSCLC, metastaticCheckMate 026: A phase 3 trial of nivolumab vs investigator's choice (IC) of platinum-based doublet chemotherapy (PT-DC) as first-line therapy for stage iv/recurrent programmed death ligand 1 (PD-L1)-positive NSCLC. Ann Oncol. 2016;27(suppl 6):vi552-587.

61. NCT1450761. Trial in extensive-disease small cell lung cancer (ED-SCLC) subjects comparing ipilimumab plus etoposide and platinum therapy to etoposide and platinum therapy alone [www.clinicaltrials.gov]. Accessed 1 Dec 2016.

62. NCT02763579. A study of carboplatin plus etoposide with or without atezolizumab in participants with untreated extensive-stage small cell lung cancer [IMpower133] [www.clinicaltrials.gov]. Accessed 1 Dec 2016.

\section{Submit your next manuscript to BioMed Central and we will help you at every step:}

- We accept pre-submission inquiries

- Our selector tool helps you to find the most relevant journal

- We provide round the clock customer support

- Convenient online submission

- Thorough peer review

- Inclusion in PubMed and all major indexing services

- Maximum visibility for your research

Submit your manuscript at www.biomedcentral.com/submit
C Biomed Central 